\title{
Leitura-paixão: o impacto de uma situação diferenciada
}

\author{
Passion in reading: \\ the impact of a new situation
}

\author{
Lucinea Aparecida de REZENDE*
}

Resumo: Durante dois anos (2003/2004), alunos da Graduação, participantes do Projeto "Leitura-paixão: o impacto de uma situação diferenciada" - vivenciaram a leitura de textos variados, inclusive com aqueles que são leitores assíduos e produzem textos de diferentes formas, por meio de suportes múltiplos. Em desenvolvimento na Universidade Estadual de Londrina e coordenado pela autora, o Projeto nasceu da constatação, em tese de doutoramento por ela defendida, da pouca e não-suficiente leitura na Graduação. Teve como objetivos: estudar leitura; oferecer aos estudantes múltiplas situações de contato com a leitura - encontros pessoais e virtuais - através de leitores e leitoresescritores, criando e/ou fortalecendo hábitos de cultivo da leitura; verificar o impacto provocado nos alunos, em uma situação diferenciada da que ocorre em sala de aula, no que se refere à formação continuada do leitor e; construir, coletivamente, uma obrareferência (livro) para professores, graduandos e pós-graduandos, tratando de leituras múltiplas. Três situações específicas permitiram, aos graduandos, aproximações com textos e/ou leitores assíduos. Uma delas diz respeito às reuniões semanais dos participantes do Projeto e a outra a encontros pessoais com palestrantes, mensalmente. Uma terceira é virtual e desenvolveu-se em grupo de discussão, na Internet. Os resultados apontam para a confirmação da hipótese de que a ambiência de leituras múltiplas é fundamental na formação de leitores, independentemente de faixa etária ou nível escolar em que se encontrem.

Palavras-chave: leitura na graduação, leitura e visão de mundo, leituras múltiplas

Abstract: For two years (2003/2004) graduation students - taking part in the project "Passion in Reading: the impact of a new situation"- experienced the reading of varied texts, including those who are assiduous readers and who produce texts of different

\footnotetext{
* Doutora em Educação pela UEL. Professora do Departamento de Educação da Universidade Estadual de Londrina - UEL. Email: lucinea@uel.br
}

Olhar de professor, Ponta Grossa, 8(1): 107-126, 2005. 
forms using multiple supports. The project, developed at the State University of Londrina and coordenated by the author, originated during the elaboration of her doctorate thesis when it was noticed that there is little and insufficient reading in the graduation courses. The aims of the project were: study reading; offer the students various situations of getting in touch with reading - with meetings in person or through the Internet - with writers and reader-writers, creating and/or strenghthening reading habits; verify the impact of this on the students in a different situation from the usual classroom one regarding the on-going formation of the reader; and build, collectively, a work of reference (book) dealing with various texts, for teachers, undergraduates and post-graduates. Three specific situations allowed the undergraduates to get in touch with texts and/or assiduous readers. One of these situations was weekly meetings for the participants of this project and another was monthly meetings with lecturers. A third situation was the virtual one which developed into group discussions on the Internet. The results confirm the hypothesis that the ambience of multiple readings is fundamental in developing reading habits, independent of age group or school level.

Key words: reading in graduation, reading and outlook on the world, multiple readings

Estudantes do curso de Ciências Sociais em final da Graduação foram indagados a respeito de como pensavam o exercício da profissão, para a qual se preparavam e na qual provavelmente ingressariam. A resposta, dada por uma aluna em nome da classe, foi: "Professora, a gente tem tido tantas coisas para ler, neste curso... é tanto 'xerox', que, para dizer a verdade, não temos tido tempo para pensar". O impacto causado pela resposta recebida levou à pesquisa da leitura na Graduação ${ }^{1}$. O objetivo foi conhecer, em um primeiro momento, $\mathrm{o}$ envolvimento do aluno de graduação com a leitura em geral; em seguida, a leitura no âmbito acadêmico, especificamente. Os dados da pesquisa expressam a pouca leitura não-acadêmica e a insuficiente apropriação, por parte dos estudantes, da leitura acadêmica.

Tendo-se presente os resultados encontrados, foi elaborado o Projeto $^{2}$ "Leitura-paixão: o impacto de uma si-

\footnotetext{
${ }^{1}$ Pesquisa de doutoramento: "Ler ou pensar: uma escolha a ser feita na Graduação? Estudo de caso". Lucinea Aparecida de Rezende. Orientador: Francisco Cock Fontanella. Piracicaba, Brasil: UNIMEP, 2004.

${ }^{2} \mathrm{O}$ projeto começou em março de 2003, com duração prevista para até março de 2005. Conta com outros professores do Departamento de Educação, de Artes, de Jornalismo, de Letras e Comunicação da UEL, além de escritores, críticos de cinema e outras pessoas, de diferentes segmentos sociais. Os alunos participantes, de graduações diversas e em diferentes séries, têm demonstrado especial interesse em relação ao Projeto.
}

108 Olhar de professor, Ponta Grossa, 8(1): 107-126, 2005. 
tuação diferenciada", desenvolvido na Universidade Estadual de Londrina - UEL", no período de março de 2003 a março de 2005. Duas hipóteses nortearam a pesquisa: a primeira, que os alunos - lembrando que muitos deles serão professores, o que é duplamente preocupante no caso de não-leitores - têm um handicap grande em relação à leitura. Assim, se faz necessário criarmos situações de vivência com o livro e com as leituras em geral, incluindo-se a leitura da imagem, e também com leitores assíduos, visando-se auxiliar aos estudantes de maneira mais incisiva quanto à sua formação como leitores. A segunda, que a escola e a universidade, enquanto instituições formadoras, têm privilegiado a palavra escrita e esse privilégio se reveste de características ímpares, visto que o professor, em princípio supostamente formador de leitores, também lê pouco (SILVA, 2003; SILVA, 2001; SANTOS, 1999; $12^{\circ}$ COLE, 1999; LAJOLO, 1994). Lê o essencial para o desempenho das suas atividades escolares/acadêmicas. Por outro lado, este início de século é marcado pela presença forte da imagem em nosso dia-a-dia. A TV, o cinema, o teatro, outdoors, placas e letreiros em geral são exemplos dessa preescola/ universidade tem-se descuidado da leitura da imagem.
Considerando-se a leitura do ponto de vista metodológico no processo ensino-aprendizagem, os objetivos do Projeto foram: estudar leitura; oferecer aos estudantes múltiplas situações de contato (encontros pessoais e virtuais) com a leitura, com a contribuição de diferentes leitores e produtores de texto, criando-se e/ou fortalecendo hábitos do cultivo de ler; e verificar o impacto provocado nos alunos, em uma situação diferenciada da que ocorre em sala de aula, no que se refere à formação continuada do leitor. $\mathrm{O}$ estudo teve como proposta encontrar pistas que nos levem a repensarmos e reorientarmos o trato com a leitura em sala de aula.

Duas situações específicas permitiram, aos graduandos, aproximações com leitores assíduos. Uma delas, efetivada através de encontros pessoais; e a outra, virtualmente. Os encontros pessoais foram subdivididos em duas vertentes, a semanal e a mensal. Semanalmente, encontraramse os participantes da pesquisa. Mensalmente, quando também se abriu espaço para convidados em geral, esse mesmo grupo recebeu um palestrante. A discussão virtual foi efetivada pelo grupo de pesquisa, que focalizou a leitura - inclusive os eventos mensais -, utilizando-se da Internet ${ }^{3}$.

\footnotetext{
3 Disponível em: < http://br.groups.yahoo.com/group/leiturapaixao >, E-mail: eiturapaixao@yahoogrupos.com.br 
Entendemos ser desejável que os estudantes tenham convivido de maneira agradável com textos em suas casas - e, é claro, na escola - ao longo de suas vidas, tornando-se leitores assíduos. No entanto, se essa ambiência de leitura não ocorreu da maneira que gostaríamos, havemos de criar oportunidades para que venha a ocorrer, não importa qual seja o nível de escolaridade em que o estudante esteja, o que inclui a Graduação. Se ele não é ainda leitor assíduo, carece de ser compreendido e tratado dessa forma; só assim conseguiremos auxiliá-lo devidamente. Dizendo de outra forma, não basta que solicitemos leituras; é preciso que auxiliemos os graduandos a lerem mais e melhor. Com esse objetivo elaboramos o Projeto "Leitura-paixão: o impacto de uma situação diferenciada".

\section{ENCAMINHAMENTOS TEÓRICO- PRÁTICOS}

Convidamos palestrantes para falarem aos alunos acerca das leituras que faziam e das suas especificidades. O que têm em comum esses convidados palestrantes? Em primeiro lugar, serem identificados por nós e pela comunidade em que vivemos, como leitores. O que nos motivou a convidálos foi o fato de considerarmos que era/é impossível desenvolverem seus trabalhos sem lerem amplamente, ou seja, sem lerem diferentes tipos de textos. A julgar pelas nossas relações de pares acadêmicos, eles aparenta- vam ser leitores assíduos. Essa aparência deveu-se a comentários de leituras em conversas, no cotidiano da Universidade, o que inclui reuniões de trabalho e conversas informais, mas também referências positivas de docentes e discentes, concernentes às suas práticas de pesquisa e ensino. Está nesse âmbito o comentário dos alunos explicitando ser prazeroso e significativo assistir às aulas de alguns desses pales-trantes, que foram seus professores. Considerou-se, ainda, a presença de alguns desses profissionais em razão de serem pesquisadores, colaboradores na Rádio FM Universitária e também em sites de provedores da Internet e dirigirem peças de teatro, apresentadas na cidade de Londrina. Essas foram, inclusive, as razões que nos levaram a convidá-los para compartilharem artigos conosco, formalizando assim reflexões acerca da leitura e expressando-as em palestras no Projeto, ao grupo de pesquisadores e convidados, sendo estes pessoas interessadas nas temáticas propostas. Como parte das atividades, os estudantes-pesquisadores optaram por entrevistar os palestrantes antes de cada evento, como uma oportunidade a mais de aproximação das suas idéias.

Há que se ressaltar que não estamos nos referindo apenas à leitura da palavra. Compreendemos texto como unidade de significação. A leitura, nesse contexto, implica o texto escrito e também as idéias expressas pelo autor por outros meios: a foto- 
grafia, a mídia, o cinema, a escultura, a pintura, o desenho, a música, a perfor-mance, a instalação artística, um clip, ou outra forma possível de expressão. Essa concepção encontra eco em FÁVERO E KOCH (01/09): o texto é "uma unidade significativa complexa, de natureza não apenas lingüística". Mais ainda: "sofre intervenções do contexto de uma forma geral e ampla" (LOPES e MENDONÇA, s/d).

A interlocução bibliográfica foi feita, dentre outras adiante nomeadas, a partir da idéia de "intermediação" e dos paradigmas sócio-culturais, conforme tratados por Vygotsky (1991a e 1991b). Partilhamos com o autor a compreensão de que o homem é um sujeito histórico, que se desenvolve e transforma na relação com o outro, com o seu contexto e sua cultura. Temos, na situação de formação de leitores, não só a intermediação do outro, o leitor, mas também a intermediação do próprio texto na construção do repertório que constitui a visão de mundo do estudante, participante do Projeto. Ao caminharmos nesse sentido procuramos ampliar contextos, oferecendo instrumental aos alunos a fim de que os múltiplos textos - palavra e imagem - viessem a fazer sentido para eles. O sentido do qual falamos é aquele que se constrói, conforme escrito por Paulo Leminski - Só buscar o sentido faz, realmente, sentido.

Tirando isso, não tem sentido (Leminski, 1997, p. 11). Queremos evi- denciar a importância de contarmos com um referencial de leitura múltiplo, ou seja, com diferentes tipos de texto. Neste caso, escolhemos a poesia para expressarmos nossos pensamentos.

A hipótese norteadora da pesquisa é a de que a ambiência de leitura é fundamental na formação de leitores. Por ambiência estamos entendendo o manusear livros e textos em geral diferentes tipos de leitura -, falar deles, escrever a respeito e particularmente trocar informações com terceiros - o professor, alunos, palestrantes-leitores, leitores diversos acerca de leituras; enfim, ter-se como algo absolutamente cotidiano e referencial a relação com múltiplos tipos de textos e leitores.

Outro nosso interlocutor é Paulo Freire, em particular no tocante às concepções de leitura e visão de mundo, apreendidas nas obras "A importância do ato de ler" (FREIRE, 1985) e "Pedagogia da Autonomia" (FREIRE, 1997). O que se pretende é que o universo vocabular dos discentes seja constituído de palavras "grávidas de mundo", conforme disse o autor (Freire, 1985, p. 23). Entendemos que

o conhecimento do maior número possivel de tipos variados de texto é, sem dúvida, um componente essencial para o desenvolvimento de estratégias de leitura, especialmente a predição, pois conhecendo a função social dos textos, os tipos de discurso 
que neles predominam, e as formas como eles são estruturados, o leitor pode chegar a compreendê-los de maneira mais eficaz e mais rápida, chegando também a reconhecê-los e distinguilos facilmente, porque a tendência do leitor é internalizar as superestruturas (formatos, linguagem, intenções) desses textos... ${ }^{4}$ (Silveira, Internet, 26-01-05).

Acreditamos que as diferentes leituras se retroalimentam; queremos dizer com isso que a aproximação feita em direção a diferentes tipos de textos - pela leitura direta e também pela interlocução com leitores assíduos -, bem como a apropriação deles pelos estudantes, pode levar estes a melhorarem sua performance enquanto leitores, compreendendo mais profunda e amplamente o que é lido. Em última instância, temos a hipótese de que o estudante lê pouco porque não conhece as possibilidades amplas de leituras possíveis de serem feitas e também porque lendo pouco, lê mal e devagar, o que acaba sendo um impeditivo para ler continuamente.

Há que se ler exercendo a máxima de que com aquilo que conhecemos bem, podemos até brincar... Então, o que se espera é que os estudantes tenham um contato tão natural e contínuo com leituras e textos, que elas acabem sendo percebidas e exercidas como uma necessidade vital. Que seja algo com o que se possa lidar como quem brinca - um ato lúdico -... sem tensões relacionadas exclusivamente à condição de "ter que ler", conforme relataram em pesquisas ${ }^{5}$ alguns acadêmicos, que só exercem a leitura conforme eles próprios disseram, como "obrigação escolar".

Poderíamos dizer: mas a ambiência de leitura já não ocorre em sala de aula? A resposta é não, se considerarmos o sentido que se dá ao que se faz (lê) e o uso de textos de caráter exclusivamente acadêmico, em sala de aula. Pesquisas já divulgadas, mencionadas anteriormente, mostram que significativa parte dos estudantes da Graduação tem lido apenas como cumprimento de dever - fazer o que o professor solicita.

Pretendemos com o referido Projeto, ou seja, com uma situação de leitura diferenciada daquela que ocorre em sala de aula, que o estudante tenha a ambiência de leitura como algo a que atribui seu próprio sentido, construído coletivamente, na interação com o outro - leitor. Procuramos oferecer condições para que ele fosse percebendo outras possibilidades

\footnotetext{
${ }^{4}$ Disponível em: < http://www.cedu.ufal.br/Revista/Revista04/mine.html >. Acesso em 26 jan. 2005.

${ }^{5}$ Ver, dentre outras pesquisas: REZENDE, L. A. Ler ou pensar - uma escolha a ser feita na graduação? Estudo de caso. Tese (Doutorado) - UNIMEP, 2002. Orientador: Francisco Cook Fontanella.
}

112 Olhar de professor, Ponta Grossa, 8(1): 107-126, 2005. 
de leitura para além daquelas que conhece, para que percebesse novos sentidos nos textos - aqueles atribuídos por palestrantes e pelos outros alunos e professores integrantes do Projeto, e para que esses textos pudessem ser resignificados por ele, frente aos seus conhecimentos já consolidados. Propiciamos, com essas condições, a possibilidade de o estudante situar-se frente ao universo textual em seus múltiplos suportes, considerando-se a palavra e a imagem. Enfim, criamos condições para que ele pudesse descobrir possibilidades diversas de leitura e fazer dela uma "ponte" contínua no construir de sua visão de mundo e no situar-se nele.

A concepção de leitura que permeia este Projeto está centrada na relação que o leitor estabelece com o texto - palavra, imagem, som. É nessa relação leitor-texto que se dá a leitura. O que é lido não está apenas no texto: está no texto e também no leitor, com aquilo que ele leva para a leitura que faz: sua experiência de vida, seus conhecimentos prévios, seu universo vocabular e conceitual. Um livro de Física, de Sociologia, sem um ser humano para lê-lo, não passa de papel e manchas de tinta
(SHEPARD 6 apud HORGAN, 1998, p. 288, in REZENDE, 2002). Importa o texto e o contexto, como nos lembra Bakhtin.

Por último, cabe explicitar que tomamos como pressuposto a leitura enquanto matéria prima em sala de aula. Dizer isso implica afirmar que a leitura não tem sido vista como algo a ser cultivado "em si"; ela é tratada apenas (?) como solicitação do professor, ainda que corriqueiramente denunciemos, em nosso dia a dia como professores, as dificuldades de leitura encontradas pelos alunos. Evidenciamos, portanto, que o nosso estudo vai ao encontro do que disse o cartunista e escritor Ziraldo, pela boca do Menino Maluquinho e em inúmeras entrevistas pelo Brasil afora: "ler é mais importante que estudar" ". Indo para o extremo oposto e considerando o que disse um aluno da Graduação: "leio para a Universidade e desejo esquecer tudo depois" (RESENDE, 2002), pesquisamos indicadores que apontem caminhos que nos levem a trabalhar a leitura de maneira a formarmos leitores. Nossa idéia é que o primeiro passo a ser dado no tratamento texto-leitor, na Graduação ${ }^{8}$, é levar o aluno a interessar-se pela leitura. Para saber como fazer isso, ou

\footnotetext{
${ }^{6}$ Shepard, Roger. Psicólogo de Stanford.

${ }^{7}$ Ziraldo comandou o painel "Ler é Mais Importante que Estudar" no Centro de Convenções de Goiânia, de 22 a 25 de maio de 2004. Disponível: < http://www2.opopular.com.br/ anteriores/... >. Acesso em: 19 jan. 2005.

${ }^{8}$ Essa questão não se refere apenas à Graduação, mas a todos os níveis de ensino. Referimonos à Graduação por ser este o nosso foco de pesquisa.
} 
ao menos contar com indicadores seguros a respeito de como fazê-lo, propusemos a pesquisa.

Tomamos como indicador a nortear nosso caminho as leituras possíveis no século XXI. A mundialização, também chamada globalização, e as implicações presentes, como, por exemplo, a da rede mundial de comunicação (www), estão a se fazer sentir culturalmente. Tem-se, nesse universo, paralelamente às questões econômicas, que nos afetam, a rapidez da comunicação e a presença significativa da imagem, concorrendo com a palavra escrita. No entanto, a escola/universidade, em sua grande maioria, parece não estar suficientemente atenta para essa possibilidade. Continuamos voltados para a palavra escrita, na mesma proporção que o fazíamos há vinte anos. E mais: parece que definimos nossas ações a partir de um modelo de aluno, que consideramos ideal. Todavia, o aluno real com o qual nos envolvemos (ou não) está a nos dizer, muitas vezes, de maneira implícita, o quão distante está do leitor que gostaríamos que ele fosse.

Enquanto nossa atenção ainda está voltada essencialmente para a escrita, na escola/universidade, as imagens estão em nosso cotidiano, fazendo-se ler: a imagem da mídia, da $\mathrm{TV}$, do cinema, da fotografia, da pintura, da escultura e de outras formas possíveis, como já citamos anteriormente. Assim, temos uma situação atípica: estamos voltados para o texto escrito e os estudantes, por sua vez, têm demonstrado forte ligação com a imagem. Jogos, filmes e a Internet apontam para essa opção, em que outros componentes, tais como o lúdico, fazem parte dessas escolhas. Nesse quadro, os alunos não estão demonstrando o interesse que pensamos ser desejável para o texto escrito, conforme apontam pesquisas na área (INEP, 2003; REZENDE, 2002; FERNANDES, 1999; OLIVEIRA e MÁS, 1999; ZACCUR, 1999). Por outro lado, não temos alfabetizado nem nós, professores, o fomos para a leitura de imagens e sons, e ela está sendo explorada sem que sejamos - nós, professores, e nossos alunos - leitores críticos dessa modalidade de texto. Pensamos que, ao atentarmos para essas questões, temos a imbricação dos suportes de leitura e da contextualização do texto e do leitor, tomados em seu sentido amplo.

A percepção desse quadro, bem como o posicionamento de acordo com ele, já acontecem em outras instituições. Temos notícia de uma Universidade de Minas Gerais e outra da Bahia, que já incluem filmes em seus vestibulares. Na UNISINOS, em São Leopoldo, alguns cursos utilizam filmes e sites desde a seleção do candidato a uma vaga. Há que se destacar que é analisado o nível de percepção do candidato: de um filme, um documentário ou sites. Para ingres- 
sar nas graduações, o candidato terá de expressar em uma redação o que percebeu com a exibição da obra apresentada no momento da prova (ZEROHORA, 2003).

Portanto, não estamos sós, ao optarmos por trabalhar a leitura em sua pluralidade, entendida como leitura da palavra e também da imagem, dos sons e silêncios, e das representações em geral. Autores como Orlandi (2001, p. 47) já se posicio-naram a respeito: procurei chamar a atenção para o fato de quê (sic) na constituição do sujeito leitor, a escola tem excluído a relação dele com outras linguagens que não a verbal.

Com essas referências foram organizadas as palestras mensais. Em outra situação - virtual -, os participantes contaram com endereço de grupo de discussão acerca da Leitura, na Internet. Mantivemos assim, via Internet e também em encontros semanais, a possibilidade de trocas de informações acerca de autores e obras diversas, bem como endereços de diferentes sites que tratam da leitura em enfoques variados. Em um sistema de tele-leitura, foram oferecidos subsídios aos acadêmicos, no campo da leitura (leitura enquanto visão de mundo, além de subsídios técnicos para o ato de ler).

No período de 2003 a início de 2005 recebemos 42 alunos. Alguns vieram em busca de conhecer a proposta que fazíamos; outros, gostariam de parti- cipar, mas os horários das atividades eram incompatíveis com seus afazeres. Outros mais, permaneceram no Projeto em interregnos de cursos, estágios e/ou trabalho assumido. Alguns fizeram parte do Projeto até o final dos trabalhos. Registramos que a quase totalidade dos estudantes que chegaram ao final, esteve ligada às atividades desde o início. Há que se destacar que muitos deles permaneceram no grupo por mais de um ano e os demais por todo o período que durou a pesquisa.

Projetamos 16 palestras e todas elas foram realizadas, ao longo do Projeto. Proferiram palestra: um escritor, um chargista, um crítico de cinema,um fotógrafo, uma professora da área da Lingüística e uma de francês, um professor de artes e um de teatro, um especialista em Leitura em quadrinhos e outro em Literatura de Cordel, uma especialista na obra de Bispo do Rosário, uma musicista e um pesquisador da cidade de Londrina e região.

\section{OVIRTUAL}

Vivemos a leitura também na modalidade virtual, o que significou, para muitos, a iniciação no uso do computador. Os gráficos seguintes expressam as experiências vividas pelo grupo. 
Gráfico 1: Demonstrativo das interações virtuais em 2003

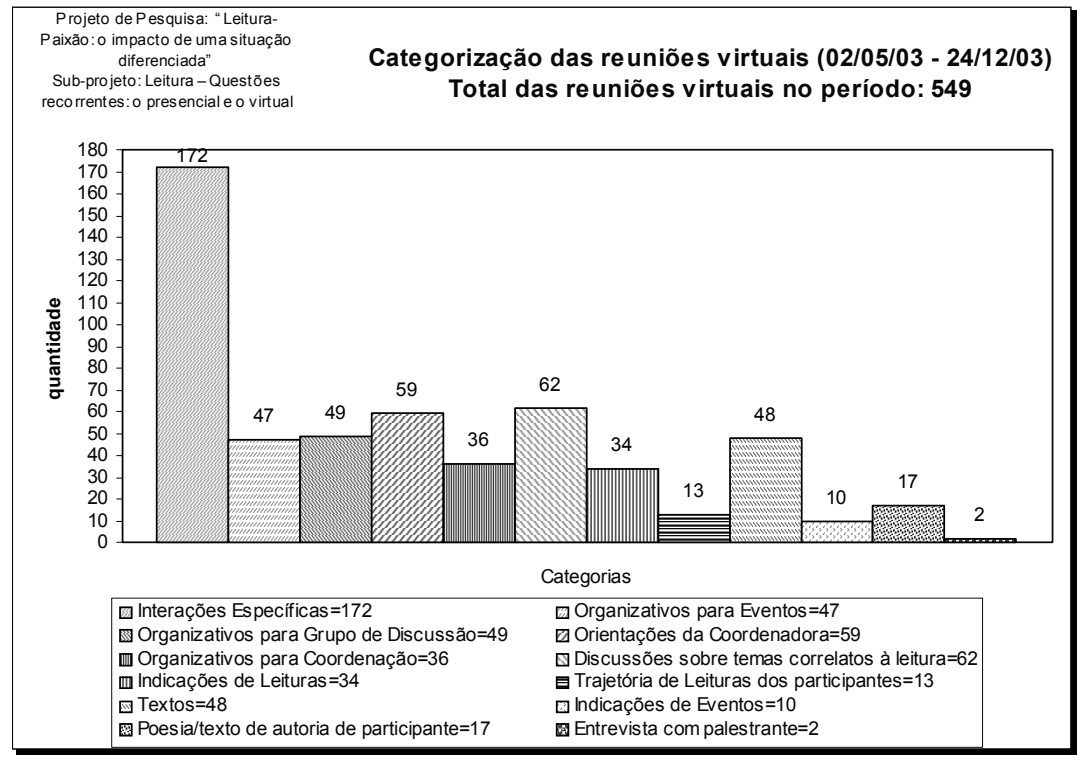

Gráfico 2: Demonstrativo das interações virtuais em 2004

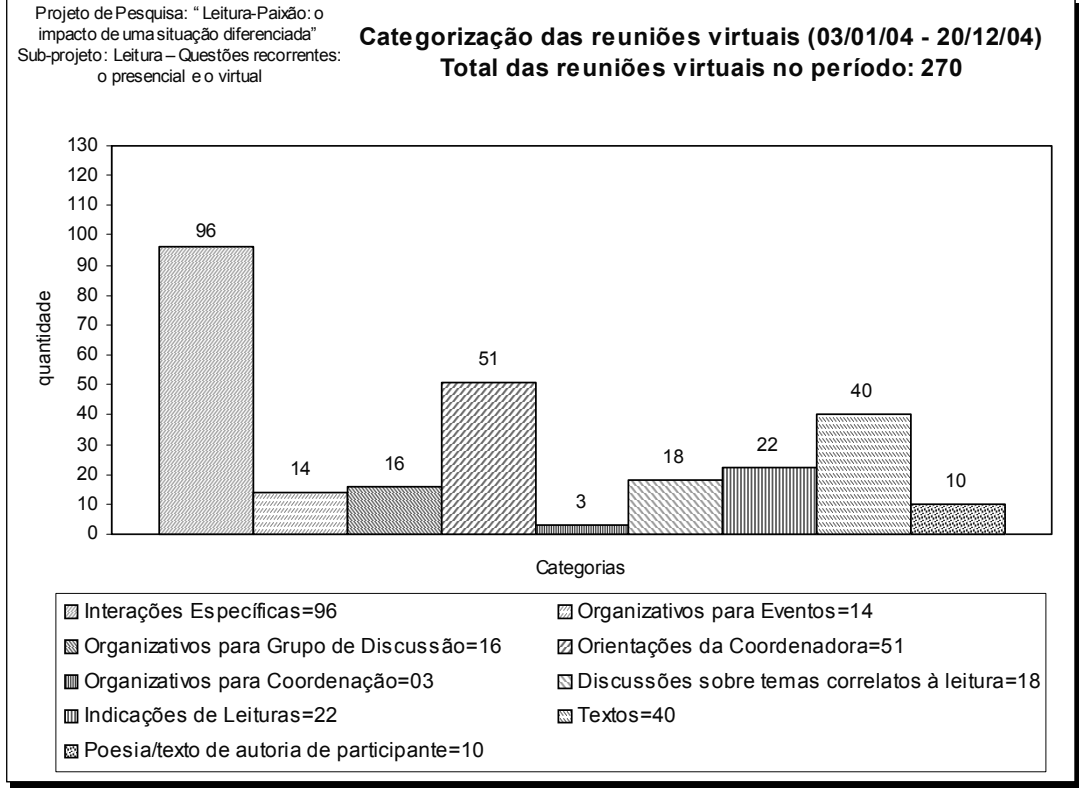

$\overline{116}$ Olhar de professor, Ponta Grossa, 8(1): 107-126, 2005. 


\section{AVALIAÇÕES}

Os participantes foram avaliados de acordo com fichas, que foram preenchidas por eles após cada evento (palestra) e outras, preenchidas pelos professores dos cursos que freqüentam (apenas três professores devolveram as fichas preenchidas). A avaliação dos professores foi solicitada com os objetivos de identificar o comportamento do/a aluno/a, no cotidiano da sala de aula e verificar como o/a aluno/ a participante do Projeto desempenha suas atividades em sala de aula, em relação aos outros alunos da sala.

Frente aos valores obtidos e considerando-se que se a escala que propusemos variou de 0 a 4 , podemos dizer que quanto ao primeiro objetivo, o da avaliação do aluno em relação a ele próprio, teríamos 75 , se o valor máximo fosse 10 . No segundo caso, do aluno em relação classe, teríamos 63. Portanto, valores acima de $70 \%$ no primeiro caso e de $60 \%$ no segundo.

Os estudantes foram avaliados também por portfólios; essa foi uma experiência para alunos e professores, visto que aprendemos juntos a lidar com esse instrumento e avaliar suas possibilidades e limites. Apenas uma parte - metade - dos alunos aceitou e desenvolveu essa tarefa. Assim, tivemos uma experiência a mais com um item no processo avaliativo, ainda que não tenhamos alcançado pleno êxito no que diz respeito participação de todos os participantes.

\section{ALGUNS COMENTÁRIOS DOS ALUNOS PARTICIPANTES DO PROJETO}

Os participantes da pesquisa teceram comentários, oralmente e por escrito, evidenciando o significado do Projeto em sua vida.

\section{$\checkmark$ Professora:}

Fiquei muito feliz em desvendar vários tipos de leituras com vc... escrevo agora ouvindo a Sonata que nos enviou e me sentido como se tivesse quatro olhos, ao ler com os meus ouvidos. Um grande abraço,

$$
\begin{aligned}
& \text { P.... } \\
& \checkmark \text { OiP, }
\end{aligned}
$$

Então, lá vai.....

Sobre a arte nas suas mais variadas formas de manifestação:

"Na arte, a aprendizagem da verdade e do belo que denuncia e revoluciona o vil da condição humana, não acontece ao acaso nem distraidamente. É dura, austera, solitária e extremamente absorvente."

“Há pois, na arte, um intenso 
processo de revelação da verdade, de manifestação do potencial escondido nas aparências. Isso produz uma imediata purificação: as sensações e as representações de nosso olhar cotidiano emudecem e a parte NOTURNA DO MUNDO, cheia de preconceitos e de mentiras, mostra-se em toda sua baixeza e solicita de nós outro cuidado."

Retirado da obra "Introdução ao Pensar: O ser, o Conhecimento, a Linguagem" de Arcângelo $R$. Buzzi, ed. Vozes, 1991, p.213 e 215.

Abraços,

Cs.

$\checkmark \quad$... Estou totalmente saudoso, daqui a três dias estarei indo a Londrina, pena que o grupo não se reúne nos feriados para um piquenique, ou mesmo para uma das elucidativas e provocativas reuniões do Projeto.

Ontem soube que está acontecendo o XIII EAIC na UEL, nossa que momento maravilhoso deve estar sendo esta semana na UEL, pessoas de diferentes universidades com diferentes experiências, e o projeto de iniciação do LeituraPaixão está sendo apresentado? Tentarei acessar o resumo no site do evento.

Boa sorte na variedade de trabalhos/orientações/aulas/pesquisas/diálogos
Abraços goiano-londrinenseiguaçuense

L.

$\checkmark$ Aprendi as novas maneiras de ver uma paisagem; agora, quando passo por um lugar bonito penso logo como, qual ângulo ficaria melhor para tirar uma foto. É impressionante (...) todas as palestras constituem-se em apenas uma: os diferentes modos de ler o mundo. (Lc)

LR, recebi seu e-mail direitinho, pelo grupo. Estou lendo um livrinho bem "inho" mesmo (livro de bolso) que peguei na biblioteca, de Schopenhauer. O titulo é "Sobre livros e leituras" Editora PARAULA Ele diz: Quando lemos, outra pessoa pensa por nós: só repetimos seu processo mental. Trata-se de um caso semelhante ao aluno que, ao aprender a escrever, traça com a pena as linhas que o professor fez com o lápis. Portanto, o trabalho de pensar nos é, em grande parte. negado quando lemos. Daí o alivio que sentimos quando passamos da ocupação com nossos próprios pensamentos à leitura. Durante a leitura nossa cabeça é apenas o campo de batalha de pensamentos alheios".

E segue dizendo: Nenhuma qualidade literária, como por exemplo, força de persuasão, riqueza de imagens, dom de comparação, 
audácia, ou amargor, ou... ...podemos adquirir lendo autores que as possuam. O que podemos é, através deles, despertar em nós tais qualidades no caso de já as possuirmos em potência, trazê-las à consciência, podemos ver tudo o que se pode fazer com elas, ....essa é a única maneira de a leitura educar-nos, na medida em que nos ensina o uso que podemos fazer de nossos dons naturais...... Sem eles, no entanto, não aprendemos com a leitura nada além de um maneirismo frio, morto e nos tornamos imitadores superficiais"

Nossa! Estou pasma. Segura essa nosso Filósofo de PLATÃO

Abraços MJ...

$\checkmark$ O Grupo gostaria de compartilhar com vocês as expressões que obtive ao receber meu portfólio. Bem acredito que não foi das melhores como a professora Lucineia disse e concordo, sou uma pessoa que cobro muito de mim e hoje tenho em mente o como isso as vezes atrapalha. Mas, no caso do portfólio ao folhe-lo (sic) novamente observei que indiretamente ele aponta algumas características minhas. Porém não gostei do retrato que delineei no portfólio, acho que no estruturei meu pensamento, $o$ trabalho não ficou organizado sistematizado (sic), no entanto a construção da segunda parte desse ajudou-me a refletir a imagem que estou passando as (sic) pessoas, ou seja, proporcionou uma leitura da minha pessoa.

Dando seqüencia nesse assunto gostaria de fazer outras colocações, algumas já retratadas em conversas e fichas de avaliação. Depois de terminar minhas colocações espero que vocês compreendam.

Uma das minhas maiores decepções ao ingressar na universidade foi realizar minha primeira avaliação de filosofia. Eram dois pensamentos o qual deveríamos comentá-los. Achei que seria o momento onde poderia colocar minhas expressões, meus pensamentos. Porém, a decepção veio e revelou que na verdade não poderia escrever o que pensava mas, o que minha professora desejava ler. E essa história vem se repetindo até hoje. Como futura pedagoga as vezes fico indignada ao saber que minha forma de pensar, o conhecimento adquirido deve moldar-se as características dos meus professores. Isso ocasionou em mim um conflito muito grande porque imaginei que na universidade poderia sair daquele mundo que me prendia e cobrava de mim comportamentos e atitudes. Vivemos em um momento social que não temos tempo de dizer, ser, ex- 
pressar o que realmente somos, estamos sempre em função de algo moda, pais, amigos...

Hoje chequei a conclusão que por muitos anos usei "Luvas" (figura de linguagem utilizada no livro a Mão e a Luva de Machado de Assis) que esconderam meu verdadeiro eu. Na verdade acho que sempre agi, de acordo com que as outras pessoas gostariam que eufosse.

Afirmo que não é fácil ser nós mesmos hoje sempre um choque de conflitos, mas deixo registrado o significado do Projeto Leitura Paixão, pois através desse coordenado pela professora Lucinia foi um dos primeiros locais onde pude expressar meus pensamentos, onde minha maneira de pensar foi respeitada e cobrada para ser registrada. Como já disse aprendi mil coisas com o projeto; umas significativas como estudante e outras como ser humano essa não mostra-se tão importante aos olhos dos outros, mas para mim tem um grande valor. E para fechar a última reunião que tivemos confirmou minhas expectativa. Como diz o ditado: não deixe para amanhã o que pode ser feito hoje; já com o projeto aprendi: o que pensamos hoje não deve ser deixamos para ser dito ou registrado para amanhã.
Enfim, obrigado a todos que direta ou indiretamente contribuiram para que eu pudesse compreender diversas formas de leitura, e que através desse processo pude encontrar-me como pessoa. Em especial um agradecimento a professora Lucinea por acreditar, incentivar,ajudar a sistematizar e estruturar os conhecimentos adquiridos.

Atenciosamente $\mathrm{M}$

$\checkmark$... professora, eu estou sentindo necessidade de ler, mas ando sem tempo... Tenho muita coisa do curso para ler. A senhora pode sugerir algum conto curto para mim? (Lc).

Acreditamos que essa aluna já é (passou a ser) leitora e não lhe bastam mais apenas os textos acadêmicos, de leitura obrigatória. Outros casos semelhantes ocorreram quando encerramos o ano de 2003 e, por sugestão do grupo, trocamos livros entre os, participantes do Projeto. Na ocasião disse uma aluna:

$\checkmark$ Que tal a gente trocar livros usados, como presente de amigo secreto? Com pouco dinheiro poderemos comprar um livro para quem for nosso(a) amigo(a) e ser um incentivo a mais leitura!

$\mathrm{P}$...

Ou ainda:

$\checkmark$ professora, incrivel como nos- 
so comportamento em relação a leitura mudou: - nós agora até já freqüentamos Sebos, vamos atrás de livros! A gente não fica mais sem eles; já não somos mais as mesmas pessoas que éramos $(\mathrm{M})$ !

$\checkmark$ Os livros não são importantes agora só na minha vida: minha mãe, minha familia também está lendo

Boa tarde professora. Passo por aqui para desejar feliz Natal e uma excelente passagem de ano. Mais uma vez paro para agradecer por todas oportunidades oferecidas, por ter acreditadoe ensinado a desfrutar de um universo que até pouco tempo era totalmente escuro e distante: o da leitura. Pode parecer mentira, mas hoje não saio sem um livro. Assim que acabou (sic) as aulas li "A Megera Domada" de Shakespeare, livro que ganhei no amigo secreto. Em seguida "Cristo Que Passa”, de Josemaria Escrivá e semana que passou fui praia e acabei levando "Os Sete Hábitos Das Pessoas Altamente Eficazes", de Stephen R. Covey e agora o próximo ser "Cem Anos de Solidão". incrível não consigo ficar de bobeira, descanso lendo. Antes quando ouvia estes comentários achava impossivel descansar lendo, no entanto percebo que esta uma das melhores formas, compreendi que descansar mudar de trabalho, ou seja, mudar de tipos de leitura.

\section{Muito Obrigada}

Atenciosamente M

Falas dos alunos, quando solicitados a avaliarem suas participações ao final do Projeto:

$\checkmark$ Fui ao supermercado e "li" a poluição sonora; vi uma paisagem bonita e pensei: se a professora Lucinea estivesse aqui ela faria a leitura do ambiente..." (E)...

No estágio não houve dúvida: optamos pela leitura como tema... (E)

Aprendi uma história que fala das mãos... mãos que nos guiam... É assim que me sinto no Projeto... Isso é muito importante na minha vida. (A)

$\checkmark \quad$ Mudei como pessoa... vou a Sebo, aprendi a mexer no computador, usar a Internet... Isso tudo faz com que eu me reveja como pessoa. Até andar de avião - primeira vez! - eu andei por causa do Projeto....(M)

O Projeto ensinou-me a confiar em minhas possibilidades $e$ saber do que sou capaz! (Lc).

Sempre achei que não gostava de ler, que a leitura era uma obrigação. Com as palestras fui verificando que não era assim;

Olhar de professor, Ponta Grossa, 8(1): 107-126, 2005. 
apenas havia algumas coisas que eu gostava e outras não... Só me arrependo de não ter entrado no início do Projeto... mas isso foi porque eu tinha medo de não dar conta das tarefas do curso e mais as do Projeto! Espero passar o que aprendi aos meus alunos. Acabei descobrindo aqui que é bom ler! (F)

$\checkmark$ Fui percebendo o tato da coordenadora do Projeto para lidar com os alunos do Projeto. Com isso eles foram adquirindo experiência ao longo do Projeto. Isso eu tive que aprender sozinho... Então aprendi muitas coisas! (Ad)

$\checkmark \quad$...Antes eu me sentia sem experiência para atuar junto a professores. Agora eu vejo a importância do Projeto na vida de cada um e na vida da Universidade. (AM).

O Projeto me deixa sempre em uma angústia filosófica e isso permite "amarrar" as idéias a outros Projetos. Percebo que posso "amarrar" os outros Projetos a partir das perspectivas que tenho no "Leitura-paixão"... Aprendo com as experiências do Grupo. Isso aqui não é só uma "coisinha" que estou fazendo... isso aqui vai- se fazer até morrer. Tenho intenção de dar aulas para crianças e adultos e acredito que o professor pode contribuir...(R)

$\checkmark$ Percebi que posso ler outras coisas... (I)

Esses são alguns registros de falas/escritos dos participantes do Projeto, manifestando o envolvimento deles com a leitura.

\section{CONSIDERAÇÕES FINAIS}

Tivemos como perspectiva inicial a participação de doze alunos no Projeto. No entanto, vendo-se relatórios de pesquisa de leitura e em conversa com pesquisadores da área de educação ${ }^{9}$, percebemos que tem sido difícil manter-se um grupo de alunos por longos períodos, em pesquisas dessa natureza. Assim, optamos por abrir espaço para a participação de vários alunos, esperando que tivéssemos, ao final, um número de estudantes próximo àquele demarcado no início do Projeto, que fizessem parte dele por um período de dois anos, segundo sua vigência, ou um período próximo a esse. Conseguimos o seguinte resultado: oito alunos da Graduação permaneceram até o final do projeto, assim como de outras três pessoas, sendo duas delas professores da rede municipal de ensino, uma das quais

\footnotetext{
${ }^{9}$ Entrevistas com, por ex., Dr.Aloysio Bzuneck, que tem, dentre outras, publicações que tratam da leitura.
} 
está cursando Especialização em Filosofia e a outra, preparando seu projeto para ingressar na Pós-Graduação (Arte). Há, ainda, uma décima primeira pessoa, que cursou disciplina especial como aluna do Mestrado em Educação, no ano de 2004. Também os os Graduandos F (Relações Públicas, curso concluído em dez. 2003) Cr (Pedagogia, $3^{\circ}$ ano /2004) e P (Relações Públicas, curso concluído em dez. 2003) permaneceram no Projeto por um ano e meio, o que dá um significativo espaço de acompanhamento das implicações da leitura em suas vidas . Um quarto aluno, L (Relações Públicas, curso concluído em dez. 2003), que esteve bastante empenhado no Projeto durante todo o ano de 2003, mudou-se para Foz do Iguaçu, onde foi fazer um estágio remunerado. A aluna S (Pedagogia, $3^{\circ}$ ano /2004) precisou deixar o Projeto em razão do trabalho que assumiu em uma escola; no entanto, passou a desenvolver um projeto de leitura nos moldes do "Leitura-paixão...", na escola em que começou a atuar como professora. A MJ mudou-se para Goiânia e seguiu como contadora de estórias naquele estado, segundo o que nos consta e de acordo com o que ela vinha fazendo em Londrina, com muita dedicação.

Os portfólios mostraram resultados satisfatórios do envolvimento dos alunos com a leitura, ainda que nem todos os estudantes o tenham entregado. Também com isso aprendemos, ou seja, vimos se apresentarem caminhos que precisam ser trilhados desde o início das atividades com portfólio, visando-se um acompanhamento mais efetivo dos trabalhos e o alcance dos objetivos propostos.

Durante todo o projeto, a sua coordenadora do Projeto foi comentando com o grupo e individualmente a respeito da participação de cada um, oferecendo diretrizes para que pudessem compatibilizar os horários das mltiplas atividades que desenvolvem, como auxiliar nos eventos, desenvolver relatório, portfólio, painel, artigo e slides para apresentação do Projeto em congressos. Os alunos L, F, Lc (a última como bolsista de Iniciação Científica 2002/3), M, P, E, A, C e A M apresentaram trabalhos em congressos. O participante Cs fez a capa do livro Leitura e visão de mundo: peças de um quebra-cabeça ${ }^{10}$, que traz figuras representativas do Projeto. Ad, um outro integrante do Projeto, não apresentou trabalhos em Congressos, porém ficou responsável pela elaboração de cartazes que expressassem, pela imagem, a mídia a ser tratada em cada palestra (evento). O aluno R está também em outro grupo de estudos de leitura em Filosofia; deseja aprofundar e divulgar idéias acerca da leitura, vivenciadas no Projeto. A alu-

\footnotetext{
${ }^{10}$ Rezende, Lucinea Aparecida de (Org.). Leitura e visão de mundo: peças de um quebracabeça. Londrina: Atrito Art, 2005.
} 
na J (Pedagogia) está como bolsista de Iniciação Científica/UEL, 2004/5, e preparando-se para apresentar sua pesquisa em congresso. Isso nos leva a afirmar que praticamente $100 \%$ dos participantes apresentaram resultados de suas participações no Projeto ao pblico em geral (junto UEL e em Congressos externos).

No que diz respeito ao segmento virtual, os dados registrados anteriormente apontam para a interação havida no grupo. Vale dizer que alguns alunos, que ao iniciarmos o Projeto resistiram ao uso do computador, tornaram-se usuários contínuos, não como quem usa o computador como máquina de escrever, mas também como quem aprendeu a usar diferentes recursos desse meio tecnológico. Houve dois casos de alunos - ou melhor, três, se considerarmos que uma situação envolve dois membros do grupo e a outra envolve um membro do grupo e uma pessoa estranha a ele - que vieram a namorar/casarse, graças aos contatos via Internet. Portanto, a Internet interferiu diretamente na vida do grupo, para além dos objetivos estabelecidos pelo Projeto.

O Projeto "Leitura-paixão: o impacto de uma situação diferenciada foi acolhido amplamente na UEL, não somente no Departamento de Educação, mas também em vários outros Departamentos, incluindo-se a rede jorna-lística - jornal escrito “Terra Vermelha e Rádio FM Universitária - que deu ampla cobertura às atividades desenvolvidas. Alunos da UEL e tam- bém pessoas da comunidade externa procuraram, assiduamente, por informações acerca do Projeto, manifestando suas intenções de participação.

O Projeto alcançou resultados positivos tanto de maneira direta, conforme os objetivos estabelecidos, como, também, de forma indireta efeitos colaterais -, para além do previsto. Um convite para tratarmos de leitura na Rádio Universitária, bem como o aumento significativo da temática "leitura nos estágios realizados pelos alunos do curso de Pedagogia, variando nos três últimos anos de $5 \%$ para $28 \%$, sendo um desses anos considerado anterior ao Projeto e os dois últimos considerados na sua vigência.

Quer nos parecer, diante dos dados encontrados, que a formação de alunos e professores leitores passa pela vivência da leitura - ambiência -, implicando o ato de ler e também o pensar coletiva e criticamente sobre esse ato, o que requer conhecer-se leitores, poder ouví-los e dialogar com eles para saber-se coisas que possam levar os alunos e nós, professores, a pensarmos e repensarmos o ato de ler diferentes tipos de textos.

O Projeto revelou-se uma experiência ímpar, apontando para situações que podem nos levar a reavaliar a leitura na Graduação. Mostrou-nos a condição dos estudantes de não-leitores assíduos e um caminho (a ambiência com leituras múltiplas) para irmos ao encontro da necessidade de 
auxiliá-los a se tornarem leitores contínuos e de múltiplos textos. Evidenciou-se, para nós, que a Universidade pode e deve ocupar esse espaço de ambiência de leitura, freqüentemente ainda não vivido pelo estudante. A continuação do Projeto - "Leitura-paixão: o impacto de uma situação diferenciada - fase II nos permitir aprofundarmos os estudos feitos.

\section{REFERÊNCIAS}

BAKHTIN, M.; VOLOCHINOV, V. N. Marxismo e filosofia da linguagem. São Paulo: Hucitec, 1995.

FERNANDES, V. Querer querer. In: $12^{\circ}$ CONGRESSO DE LEITURA DO BRASIL: MÚLTIPLOS OBJETOS, MÚLTIPLAS LEITURAS: AFINAL, O QUE LÊ A GENTE? Anais... Campinas, UNICAMP, 1999.

FILMES e sites inovam na seleção de acadêmicos. Curso de comunicação digital é novidade na UNISINOS. Jornal Zero Hora, Porto Alegre, 04 dez. 2003.

FREIRE, P. A importância do ato de ler: em três artigos que se completam. São Paulo: Cortez, 1985.

Pedagogia da autonomia: saberes necessários à prática educativa. São Paulo: Paz e Terra, 1996.

HORGAN, J. O fim da ciência: uma discussão sobre os limites do conhecimento científico. São Paulo: Companhia das Letras, 1998.

LAJOLO, M. Do mundo da leitura para a leitura do mundo. São Paulo: Ática, 2001.
LEMINSKI, P. Ensaios e anseios crípticos. Curitiba: Pólo Editorial do Paraná, 1997.

LOPES, Â. M. T.; MENDONÇA, R; H. Texto: leitura e produção de sentidos. Boletim de Língua Portuguesa, Programa $\mathrm{n}^{\circ} 3$, [s.d.].

OLIVEIRA, L. M. P.; MÁS, M. I. H. Dificuldades existem: como saná-las? In: $12^{\circ}$ CONGRESSO DE LEITURA DO BRASIL: MÚLTIPLOS OBJETOS, MÚLTIPLAS LEITURAS: AFINAL, O QUE LÊ A GENTE? Anais... Campinas, UNICAMP, 1999.

ORLANDI, E. P. Discurso e leitura. São Paulo: Cortez, 2001.

QUALIDADE da Educação: uma nova leitura do desempenho dos estudantes da $4^{\mathrm{a}}$ série do ensino Fundamental. Jornal de Londrina, Londrina, 11 mai. 2003.

REZENDE, L. A. Ler ou pensar - uma escolha a ser feita na graduação? Estudo de caso. Tese de (Doutorado) - Universidade Metodista de Piracicaba, Piracicaba, 2002.

SANTOS, I. S. Trajetórias de professores: narrativas que trazem a leitura na vida e no cotidiano escolar. In: $12^{\circ}$ CONGRESSO DE LEITURA DO BRASIL: MÚLTIPLOS OBJETOS, MÚLTIPLAS LEITURAS: AFINAL, O QUE LÊ A GENTE? Anais... Campinas, UNICAMP, 1999.

SILVA, J. M. S. O PROLER e a política de formação de professores em Caxias. In: $13^{\circ}$ CONGRESSO DE LEITURA DO BRASIL: COM TODAS AS LETRAS PARA TODOS OS NOMES. Anais... Campinas, UNICAMP, 2001.

SILVA, S. A. A leitura e a formação de professores(as). In: $14^{\circ} \mathrm{CONGRESSO} \mathrm{DE}$ 
LEITURA DO BRASIL: AS COISAS, QUE TRISTE SÃO AS COISAS CONSIDERADAS SEM ÊNFASE. CARLOS DRUMMOND DE ANDRADE. Anais... Campinas, UNICAMP, 2003.

SILVEIRA, M. I. M. Tipologia textual e estratégias de leitura. Disponível em: $<$ http://www.cedu.ufal.br/Revista/... > . Acesso em: 26 jan. 2005.

VYGOTSKY, L. S. et al. Bases psicológicas da aprendizagem e do desenvolvimento. São Paulo: Moraes, 1991a.

. Pensamento e linguagem. São Paulo: Martins Fontes, 1991b.

ZACCUR, E. Ser leitor e/ou ledor: eis a questão. In: $12^{\circ} \mathrm{CONGRESSO} \mathrm{DE} \mathrm{LEI-}$ TURA DO BRASIL: MÚLTIPLOS OBJETOS, MÚLTIPLAS LEITURAS: AFINAL, O QUE LE A GENTE? Anais... Campinas, UNICAMP, 1999.

Encaminhado em 21/03/05

Aceito em 06/07/05 